\title{
Relationship Between the Expression of S100P in Gastric Cancer Tissue and Clinical Pathology
}

\author{
Hou Jianzhang ${ }^{1,2}$, Li Yong ${ }^{1, *}$ \\ ${ }^{1}$ Third Department of Surgery, Fourth Hospital of Hebei Medical University, Shijiazhuang, China \\ ${ }^{2}$ Hepatobiliary Pancreatic (Minimally Invasive) Surgery Ward, Cangzhou People's Hospital, Cangzhou, China
}

Email address:

Li-yong-hbth@126.com (Li Yong)

${ }^{*}$ Corresponding author

\section{To cite this article:}

Hou Jianzhang, Li Yong. Relationship Between the Expression of S100P in Gastric Cancer Tissue and Clinical Pathology. American Journal of Clinical and Experimental Medicine. Vol. 9, No. 3, 2021, pp. 55-64. doi: 10.11648/j.ajcem.20210903.12

Received: April 20, 2021; Accepted: May 19, 2021; Published: May 24, 2021

\begin{abstract}
Purpose: Discuss the diagnosis value and action mechanism of S100P for gastric cancer and the influence of S100P in tumor metastasis. Method: Collect 100 cases of gastric cancer tissues diagnosed as per histopathology by our hospital, apply immunohistochemistry method, test the positive expression condition of S100P protein, compare with 100 cases of control tissue specimens, and analyze the relationship between S100 protein expression condition in gastric cancer tissue and clinical pathology. Result: the positive rate $(51.0 \%)$ of S100P in gastric cancer tissue is significantly lower than chronic atrophic gastritis with atypical hyperplasia, superficial gastritis and normal gastric mucosa $(\mathrm{P}<0.001$ or $\mathrm{P}<0.05)$, while the difference between gastric cancer group and group of chronic atrophic gastritis with atypical hyperplasia has no statistic significance $(\mathrm{P}>0.05)$. The difference of positive rate of S100P in gastric cancer tissue with gender, age, tumor size, tumor position and Lauren typing has no statistic significance. In well differentiated adenocarcinoma, moderately differentiated adenocarcinoma, poorly differentiated adenocarcinoma and adenocarcinoma anaplastic, the positive rate $(80.56 \%)$ of S100P of the three groups has significant difference $\left(\chi^{2}=13.912, \mathrm{P}=0.001\right)$. The positive rate of $\mathrm{S} 100 \mathrm{P}$ which doesn't invade serosa is significantly higher than the positive rate $\left(34.38 \%, \chi^{2}=19.662, \mathrm{P}<0.001\right)$ of S100P invading serosa and invading beyond the serosa, and the difference of positive rate of S100P of Phase I, Phase II, Phase III and Phase IV also has statistic difference $\left(\chi^{2}=13.347, \mathrm{P}=0.004\right)$, the positive rate $(73.17 \%)$ of localized S100P protein is significantly higher than the positive rate $\left(35.59 \%, \chi^{2}=13.669, \mathrm{P}<0.001\right)$ of invasive type; the positive rate $(74.42 \%)$ of $\mathrm{S} 100 \mathrm{P}$ without lymph node metastasis is significantly higher than the positive rate $\left(33.33 \%, \chi^{2}=15.020\right.$, $\mathrm{P}<0.001$ ) with lymph node metastasis. Conclusion: the positive rate of $\mathrm{S} 100 \mathrm{P}$ protein in gastric cancer tissue is significantly lower than the para-carcinoma tissue; the lower the differentiation degree is, the deeper the invasion is; the patients who have later TNM staging and Borrmanntyping, and lymph node metastasis have lower positive rate of S100P protein, which indicates that the low expression of S100P protein participates in the occurrence, development, invasion and metastasis of gastric cancer, and is an independent dangerous factor affecting the patients' prognosis.
\end{abstract}

Keywords: Gastric Cancer, S100P, Degree of Differentiation, Borrmann Classification, TNM Staging, Lymph Node Metastasis

\section{Introduction}

Gastric cancer (GC) is one of the most common cancers in the world, as well as one of the common malignant tumors of digestive tract. As per the research result of International Agency for Research on Cancer, in 2018, there were about 18.10 million new cancer patients and 9.6 million dead from cancers, including 1.03 million gastric cancer patients and accounting for $5.6 \%$ of the total cancer patients; the occurrence rate of gastric cancer is about $11.1 / 100,000$, ranking the $5^{\text {th }}$ among all the malignant tumors; about 782,000 patients died from gastric cancer, accounting for $8.2 \%$ of the death owing to tumors, with the death rate as about 8.2 / 100,000 [1]. China has high gastric occurrence rate. In 2015, China's cancer data showed that patients of new occurrence and death were about 403,000 cases and 291,000 cases respectively, with the occurrence rate and death rate as 
29.31/100,000 and 21.16/100,000 respectively, both of which ranked the $2^{\text {nd }}$ among malignant tumors [2] and exceeded by 2 times of world average level; the urban and rural difference of gastric cancer is significant, and the occurrence rate in countryside is 1.6 times of the city [3]. As gastric cancer has the features of concealment, high missed diagnosis rate, high reoccurrence rate, and death rate, etc., most of the gastric cancer patients have been at the progressive stage when they are diagnosed, which causes the low rate for having radical resection, and high occurrence rate for post-surgery reoccurrence and metastasis, with the median survival time as only 3 to 24 months, and the 5 -year survival rate as only about $40 \%[3]$. The treatment effect is relatively weak. Therefore, gastric cancer has become one of the malignant tumors which seriously threaten human health. By far, the occurrence and development mechanism of gastric cancer has not been clear. $\mathrm{S} 100 \mathrm{P}$ protein is an important member of S100 family, has the common functions of mediating cell-cell junction, protein phosphorylation, $\mathrm{Ca}^{2+}$ signal transduction, transcriptional control, etc. as other S100 family members, participates in the differentiation and maturity of normal cells with the regulation of $\mathrm{Ca}^{2+}$, so as to avoid cell damage, and participate in various pathophysiological processes of the body by mediating the $\mathrm{Ca}^{2+}$ dependent signal transduction channel [4]. Currently, relevant researches of S100P are mainly in the tumor fields. Researches discover that S100P is a new tumor marker, has abnormal expression in the tumor cells of prostatic cancer, transitional cell carcinoma of bladder, non-small cell lung cancer, etc., participates in the abnormal hyperplasia and malignant transformation, promotes the movement of tumor cells, enhances the invasion capability of tumors, plays an important role in the occurrence and development of tumors, and correlates to the clinical staging, metastasis, prognosis and drug sensitivity of the tumor. With human deepening researches for $\mathrm{S} 100 \mathrm{P}$, it is discovered that $\mathrm{S} 100 \mathrm{P}$ has potential diagnosis and treatment value in gastric cancer, pancreatic cancer, colorectal cancer and other digestive tract tumors, and may become novel antitumor targets for new diagnosis and drug treatment [7]. This research takes 100 cases of primary gastric cancer tissuesdiagnosed by histopathology as the research object, applies immunohistochemistry dyeing method, tests the expression of S100P protein in gastric cancer, normal gastric mucosa and paracancerous control tissue specimens, analyzes the relationship of the two with clinical pathology, invasion, and metastasis of gastric cancer and their correlation, and discusses its role in the occurrence and development process of gastric cancer, and its influences in gastric cancer, and provides theoretic basis for early diagnosis, prognosis evaluation and targeted therapy.

\section{Data and Method}

\subsection{Research Object}

Collect 100 patient cases from Gastrointestinal Surgery of Cangzhou People's Hospital, Department I of General Surgery of Cangzhou Central Hospital, and Surgery Department V of
Cangzhou Hospital of Integrated TCM-WM from January, 2016 to December, 2018. All the 100 cases were diagnosed as primary gastric cancer by histopathology and didn't have chemotherapy or radiotherapy before the surgery. Select 100 gastric cancer tissues of surgical resection, 40 normal gastric mucosa (with the distance to the tumor edge $>5.0 \mathrm{~cm}$ ) tissues, and 40 specimens of superficial gastritis through gastroscopy and 20 specimens of chronic atrophic gastritis with atypical hyperplasia, place them in neutral formalin buffer of $10 \%$ and fix them for 24 hours, embedded in paraffin. 3 sections of each specimen were sliced consecutively, with the thickness as $4 \mu \mathrm{m}$, with one section having HE dyeing of normal tissue for pathological analysis and the other 2 sectionshaving S100P immunohistochemistry dyeing. Collect clinical data in details, including the patients' gender, age, tumor size, tumor position, Lauren typing, differentiation degree, invasion depth, TNM staging, Borrmanntyping, lymph node metastasis, etc. There were 69 male patients and 31 female patients, with the age as 31 to 78 years old, with 21 cases less than 60 years old and 79 cases not less than 60 years old, and the average age as $(65.62 \pm 10.56)$ years old. Group as per "Standard for Gastric Cancer Diagnosis and Treatment (the National Health Commission of the People's Republic of China-Version 2011) [8], Borrmann typing [9] and TNM staging standard of (UICC/AJCC). The information of the 100 cases of primary gastric patients among the research objects are as the following:(1) gender: 69 male cases and 31 female cases; (2) age: 32 cases of less than 60 years old, and 68 cases of not less than 60 years old; (3) tumor size: 41 cases with the tumor diameter less than $5.0 \mathrm{~cm}$ and 59 cases with the tumor diameter not less than $5.0 \mathrm{~cm}$; (4) tumor position: 49 cases have the tumor at the gastric antrum, 27 cases have the tumor at the gastric body, and 24 cases have the tumor at the gastric bottom; (5) Lauren typing: 51 cases are diffusive type, 35 cases are intestinal type, and 14 cases are mixed type; (6) differentiation degree: 41 cases are poorly differentiated and undifferentiated adenocarcinoma, 32 cases are moderately differentiated adenocarcinoma, 27 cases are well-differentiated carcinoma; (7) invasion depth: 36 cases don't invade the serosa (T1+T2), and 64 cases invade the serosa and invade beyond the serosa (T3+T4); (8) TNM staging: 11 cases are Phase I; 26 cases are Phase II, 44 cases are Phase III, and 19 cases are Phase IV; (9) Borrmann typing: 41 cases are localized types (I + II), and 59 cases are invasion type (III+IV); (10) lymph node metastasis: 43 cases have no lymph node metastasis and 57 cases have lymph node metastasis.

\subsection{Research Method}

\subsubsection{Experiment Instruments and Reagents}

Main instruments: JY-TSF hydroextractor and JY-TK section water bath-slide drier (domestic), Histocore Arcadia $\mathrm{H} / \mathrm{C}$ embedding machine, microtome, BOND-MAX automatic immunohistochemical analyzer (Leica), and OLYMPUS Bx51 optical microscope (Japan). Main reagents: ILK (RabMAbs) [EP1593Y] (ab52480) Abcam (the UK) is purchased from MXB Biotechnologies, Rabbit anti human S100P polyclonal antibody [EPR6143] (ab133554) 
(ready-to-use) is from Abcam (the UK), Goat Anti-Rabbit Secondary Antibody (ready-to-use) fast immunohistochemistry Max Vision TM testing kits are purchased from MXB Technologies.

\subsubsection{Immunohisto Chemistry Dyeing}

Adopt immunohistochemistry (S-P) method to have S100P immunohistochemistry dyeing for gastric tissues, normal gastric mucosa tissue which is more than $5.0 \mathrm{~cm}$ from the tumor edge and tissue of superficial gastritis obtained through gastroscopy and tissue of chronic atrophic gastritis with atypical hyperplasia. Rabbit Anti Human S100P and S-P immunohistochemistry dyeing and DAB chromogenic agent are purchased from MXB Technologies; use known positive tissue specimen as positive control, use PBS of $\mathrm{pH} 7.4$ to substitute first antibody as the negative control, and dye strictly as per the instruction manual of the kit. The specific steps are as the following: As per the routine procedures of pathological techniques, have slide treatment, section preparation, immunohistochemistry dyeing, section sealing with neutral balsam, and then observe the immunohistoche -mistry section with microscope, and analyze and take photos.

\subsubsection{Result Judgment}

Use PBS to substitute the first antibody as the negative control, and use the known positive section as the positive control. Use optical microscope to observe the dyeing of the cells with high power lens, in case the cytoplasm and / or nucleus presents light yellow or brownish yellow particles, it is positive. S100P positiveis mainly expressed in the cytoplasm, and a minority is located at the nucleus or on the cell membrane. As per whether there are positive particles or color, the cell dyeing intensity is divided into 4 grades, with the scoring standard as: no dyeing as 0 point, light yellow as 1 point, yellow or dark yellow as 2 points, and brown as 3 points. Select 5 high power fields randomly, as per the dyeing scope, count the average of the positive cell percentage. The percentage of positive cell is divided into 3 grades: 0 point for no positive cells, 2 points for positive cell rate of $26 \%$ to $50 \%$, and 3 points for positive cell rate higher than $51 \%$. The judgment standard for dyeing result is: the product of dyeing intensity and percentage score of positive cells is the final score of each specimen: 0 to 2 points means negative (-), and 3 to 6 points means positive $(+)$. Upon overall result judgment, not more than 2 points represents negative, more than 2 points represents positive. As per the scoring standard of Wang, etc.[5], in case the cell has no positive dyeing or the positive dyeing is less than $5 \%$, it represents negative; in case the positive dyeing of the cells is more than $5 \%$, it represents positive.

\subsection{Statistic Method}

Sort out the obtained clinical data and S100P immunohistochemistry dyeing result. All the data adopts SPSS21.0 statistic software for analysis, have $\chi^{2}$ inspection for the analysis of relationship between S100P immunohistoche-mistry dyeing result and clinical parameters, express the counting data with percentage, utilize Spearman grade correlation inspection for correlation analysis; in case of $\mathrm{P}<0.05$, it indicates that the difference has statistic significance.

\section{Result}

\subsection{S100P Dyeing Condition of Gastric Cancer and Control Tissues}

The positive rate $(51.0 \%, 51 / 100)$ of $\mathrm{S} 100 \mathrm{P}$ in gastric cancer tissue is significantly lower than the control group $(83 \%, 83 / 100)$, and the difference has statistic significance $\left(\chi^{2}=28.86, P<0.001\right)$, the positive rate of gastric cancer tissue is significantly lower than that of the tissue of chronic atrophic gastritis with atypical hyperplasia, superficial gastritis, and normal gastric mucosa, and the difference among the 4 groups has statistic significance $(P<0.001$ or $P<0.05)$; through pairwise comparison, the positive rate difference of S100P of gastric cancer with superficial gastritis and normal gastric mucosa tissue has statistic significance, and the difference of gastric cancer with the group of chronic atrophic gastritis with atypical hyperplasia has no statistic significance $(P>0.05)$, as shown in Figures 1-6 and Table 1.

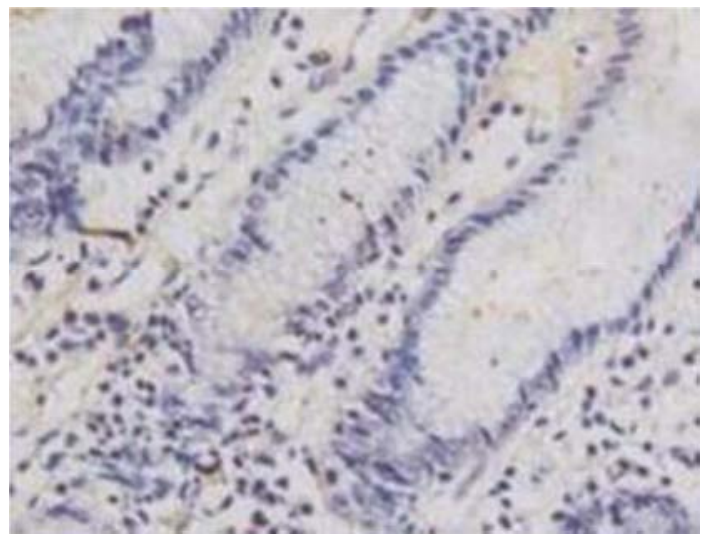

Figure 1. Negative expression of S100P in normal gastric mucosa $(\times 200)$.

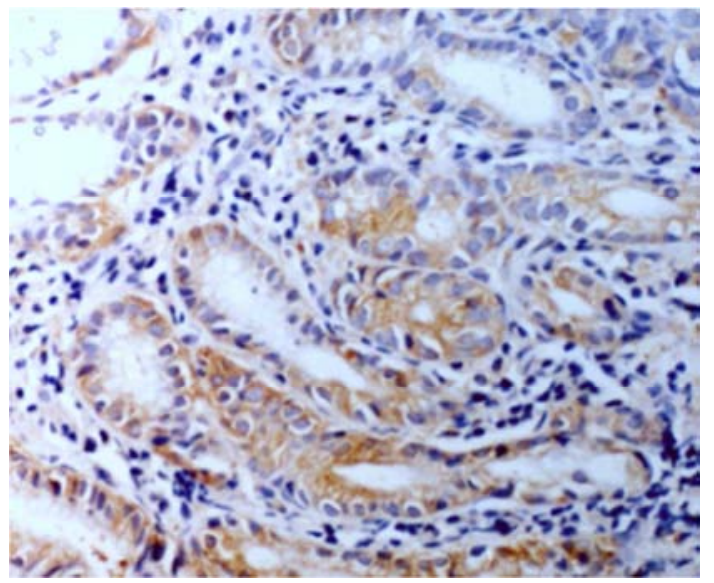

Figure 2. Positive expression of S100P in normal gastric mucosa $(\times 200)$. 


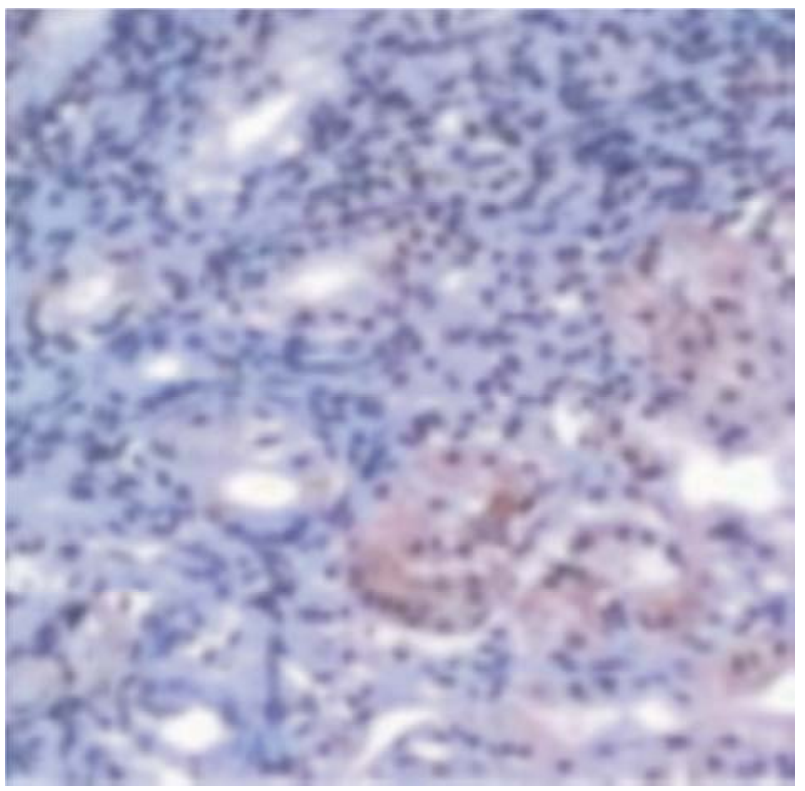

Figure 3. Positive expression of S100P in Superficial gastritis tissues $(\times 200)$.

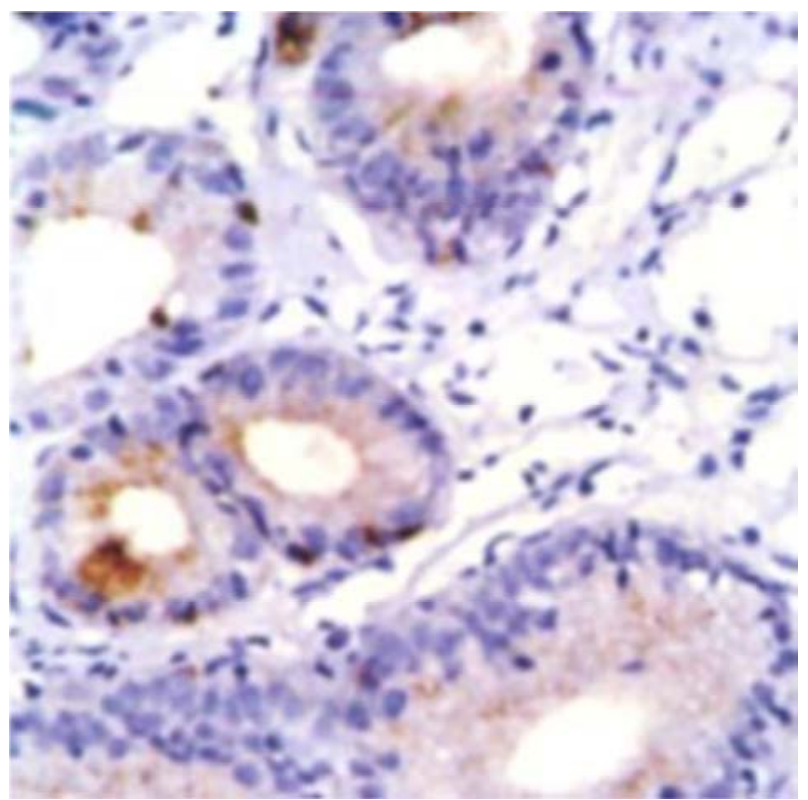

Figure 4. Positive expression of S100P in Chronic atrophic gastritis with atypical hyperplasia tissues $(\times 200)$.

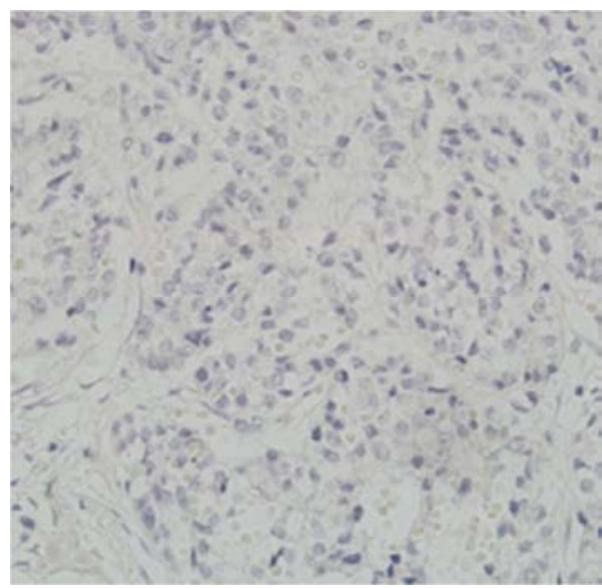

Figure 5. Negative expression of S100P in gastric carcinoma tissues $(\times 200)$.

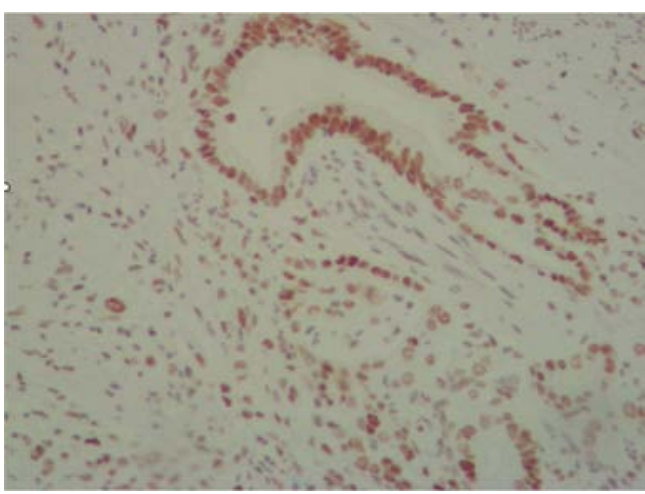

Figure 6. Positive expression of S100P in gastric carcinoma tissues $(\times 200)$.

\subsection{S100P Positive Rate Comparison of Gastric Cancer Tissue with the Control Group}

S100P positive rate difference of tissue of gastric cancer, chronic atrophic gastritis with atypical hyperplasia, superficial gastritis and normal gastric mucosa has statistic significance $\left(\chi^{2}=28.856, P<0.001\right)$, but the S100P positive rate difference of the gastric cancer with chronic atrophic gastritis with atypical hyperplasia and control group has no statistic significance $(P>0.05)$. There are 6 groups comparing each other, $\mathrm{P}=0.05 / 6=0.008$. Compared with group I and II, $\chi^{2}=1.312, P=0.252$. Compared with group I and III, $\chi^{2}=9.955$, $P=0.002$. Compared with group I and IV, $\chi^{2}=28.586, P=0.000$. as shown in Table 1

Table 1. Comparison of S100P positive rate of gastric cancer tissue and the control group [n (\%)].

\begin{tabular}{|c|c|c|c|c|}
\hline $\operatorname{group}(\mathrm{N})$ & Positive (\%) & Negative (\%) & $\chi^{2}$ & $P$ \\
\hline I group (100) & $51(51.0)$ & $49(49.0)$ & \multirow{4}{*}{28.856} & \multirow{4}{*}{$<0.001$} \\
\hline II group (20) & $13(65.0)$ & $7(35.0)$ & & \\
\hline IIIgroup (40) & $32(80.0)$ & $8(20.0)$ & & \\
\hline IVgroup (40) & $38(95.0)$ & $2(5.0)$ & & \\
\hline
\end{tabular}

Note: Group I (gastric cancer group), Group II (chronic atrophic gastritis withdysplasia), Group III (superficial gastritis), Group IV (normal gastric mucosaltissue).

\subsection{Comparison of Gastric Cancer Patient's General Clinical Features and 100P Expression}

The positive rate of S100P in gastric cancer tissues has no significant difference with the difference of patients' gender, age, tumor size and position, and Lauren typing (the $\chi^{2}$ value is $0.631,0.320,0.001,0.181$ and 0.851 respectively and the $P$ value is $0.434,0.571,0.971,0.914$ and 0.653 respectively), but the positive rate $(47.06 \%, 24 / 51)$ of S100P in diffusive gastric cancer is lower than that $(57.14 \%, 20 / 35)$ of intestinal 
type, as shown in Table 2.

Table 2. Relationship between gastric cancer patients' clinical characteristics and S100P expression [n (\%)].

\begin{tabular}{|c|c|c|c|c|c|}
\hline Clinical features & Example & Negative & Positive (\%) & $\chi^{2}$ & $P$ \\
\hline \multicolumn{6}{|l|}{ Gender } \\
\hline Male & 69 & 32 & $37(53.62)$ & \multirow{3}{*}{0.613} & \multirow{3}{*}{0.434} \\
\hline Female & 31 & 17 & $14(45.16)$ & & \\
\hline \multicolumn{4}{|l|}{ Age } & & \\
\hline$<60$ & 32 & 17 & $15(46.88)$ & \multirow{3}{*}{0.320} & \multirow{2}{*}{0.571} \\
\hline$\geq 60$ & 68 & 32 & $36(52.94)$ & & \\
\hline \multicolumn{5}{|l|}{ Tumor size $(\mathrm{cm})$} & \\
\hline$<5$ & 41 & 20 & $21(51.22)$ & \multirow{2}{*}{0.001} & \multirow{2}{*}{0.971} \\
\hline$\geq 5$ & 59 & 29 & $30(50.85)$ & & \\
\hline \multicolumn{6}{|l|}{ Tumor location } \\
\hline Antrum & 49 & 23 & $26(53.06)$ & \multirow{4}{*}{0.181} & \multirow{4}{*}{0.914} \\
\hline Stomach body & 27 & 14 & $13(48.15)$ & & \\
\hline Fundus & 24 & 12 & $12(50.00)$ & & \\
\hline \multicolumn{4}{|l|}{ Lauren typing } & & \\
\hline Diffuse & 51 & 27 & $24(47.06)$ & \multirow{3}{*}{0.851} & \multirow{3}{*}{0.653} \\
\hline Gut type & 35 & 15 & $20(57.14)$ & & \\
\hline Hybrid & 14 & 7 & $7(50.00)$ & & \\
\hline
\end{tabular}

\subsection{Relationship of Gastric Cancer Patients'S100P Expression with Its Differentiation Degree, Invasion Depth, TNM Staging and Lymph Node Metastasis}

In the differentiation degree of $\mathrm{S} 100 \mathrm{P}$ in gastric cancer, the positive rate of well differentiated, moderately differentiated, poorly differentiated and undifferentiated adenocarcinoma is $77.78 \%(21 / 27), 53.13 \%(17 / 32), 31.71 \%$ (13/41) respectively, the comparison of the three groups has significant difference $\left(\chi^{2}=13.912, \quad P=0.001\right)$; as for the invasion depth, the S100Ppositive rate $(80.56 \%, 29 / 36)$ of not invading the serosa $(\mathrm{T} 1+\mathrm{T} 2)$ is significantly higher than the positive rate $(34.38 \%$, $22 / 64$ ) of invading the serosa and invading beyond the serosa (T3+T4), the comparison of the two has significant difference $\left(\chi^{2}=19.662, P<0.001\right)$; in TNM staging, the positive rate of Phase I, Phase II, Phase III and Phase IV is $81.82 \%(9 / 11)$, $69.23 \%(18 / 26), 43.18 \%(19 / 44)$ and $26.32 \% \quad(5 / 19)$ respectively, the comparison of the four groups has significant difference $\left(\chi^{2}=13.347, P=0.004\right)$; in Borrmann typing, the positive rate $(73.17 \%, 30 / 41)$ of S100P of localized type (I+II) is significantly higher than the positive rate $(35.59 \%, 21 / 59)$ of invasive type (III+IV), and the comparison of the two has significant difference $\left(\chi^{2}=13.669, P<0.001\right)$. In lymph node metastasis, the positive rate $(74.42 \%, 32 / 43)$ of S100P without lymph node metastasis is significantly higher than the positive rate $(33.33 \%, 19 / 57)$ with lymph node metastasis, and the comparison of the two has significant difference $\left(\chi^{2}=15.020\right.$, $P<0.001$ ), as shown in Table 3 .

Table 3. Relationship of gastric cancer patient's S100P expression with its differentiation degree, invasion depth, TNM staging and lymph node metastasis [n (\%)].

\begin{tabular}{|c|c|c|c|c|c|}
\hline Pathological characteristics & Example & Negative & Positive (\%) & $\chi^{2}$ & $P$ \\
\hline \multicolumn{6}{|l|}{ Differentiation } \\
\hline Low & 41 & 28 & $13(31.71)$ & \multirow{3}{*}{13.912} & \multirow{3}{*}{0.001} \\
\hline Middle & 32 & 15 & $17(53.13)$ & & \\
\hline high & 27 & 6 & $21(77.78)$ & & \\
\hline \multicolumn{6}{|l|}{ Depth of infiltration } \\
\hline T1/T2-lessthan serosa & 36 & 7 & $29(80.56)$ & \multirow{3}{*}{19.662} & \multirow{3}{*}{$<0.001$} \\
\hline $\begin{array}{l}\text { T3/T4-Slurry and beyond } \\
\text { TNM staging }\end{array}$ & 64 & 42 & $22(34.38)$ & & \\
\hline I & TNM staging & 2 & $9(8182)$ & & \\
\hline II & 26 & 8 & $18(69.23)$ & \multirow{3}{*}{13.347} & \multirow{3}{*}{0.004} \\
\hline III & 44 & 25 & $19(43.18)$ & & \\
\hline IV & 19 & 14 & $5(26.32)$ & & \\
\hline \multicolumn{6}{|l|}{ Lymph node metastasis } \\
\hline No & 43 & 11 & $32(74.42)$ & \multirow{2}{*}{15.020} & \multirow{2}{*}{$<0.001$} \\
\hline Have & 57 & 38 & $19(33.33)$ & & \\
\hline Borrmann typing & & & & 13.669 & $<0.001$ \\
\hline $\mathrm{I}+\mathrm{II}$ & 41 & 11 & $30(73.17)$ & & \\
\hline III+IV & 59 & 38 & $21(35.59)$ & & \\
\hline
\end{tabular}

\section{Discussion}

Global gastric cancer incidence ranks the $5^{\text {th }}$ among the malignant tumors. China's incidence of gastric cancer accounts for about $44 \%$ of the world incidence of gastric cancer [1], which is only lower than the lung cancer. China's gastric cancer occurrence rate ranks the $2^{\text {nd }}$ among malignant 
tumors, while its death rate ranks the $3^{\text {rd }}$ among malignant tumors [11]. The occurrence of gastric cancer has significant regional and gender difference, about $2 / 3$ is in Asia, and about $70 \%$ is in developing countries. Gastric cancer intends to occur among population of 50 to 70 years old, and the incidence for population more than 40 years old rises gradually, the incidence for population of more than 50 years old presents "blowout" growth, the incidence for male is 2 times of female, and the incidence in regions with backward economy and poor sanitation conditions is high [12]. Besides, the detection rate of early phase gastric cancer in Japan and South Korea reaches $50 \%$ to $70 \%$, while the detection rate of China's early phase gastric cancer is just $10 \%$ to $20 \%$ [13]. In recent years, clinical researches for S100P have won a lot of attention, especially the researches on S100P family with human malignant tumors [14].

S100P preliminarily comes from S100 family separated from placenta, is a new member of S100 family and a group of low molecular weight $(9000 \sim 14000)$ calcium-binding regulatory protein. Its aminoacid sequence is highly preservative, and it is named S100P because it is soluble in $100 \%$ saturated ammonium sulfate solution. Current researches discover that S100 protein family has at least 24 members, including S100A1 S100A16, S100B, S100G, S100P, S100Z, etc. Thefamily is isomer composed of 2 subunits, and most of them exist in the form of homodimer, as well as in the form of heterologous dimer, trimer and tetramer, etc. However, the homodimer structure of S100P may be more stable than other S100 protein family members. At the C-end and $\mathrm{N}$-end of each subunit of S100P, there is one unique EF hand form structure binding with $\mathrm{Ca}^{2+}[15]$, of which, $\mathrm{C}$-end has relatively high affinity for $\mathrm{Ca}^{2+}$ while $\mathrm{N}$-end has relatively low affinity for $\mathrm{Ca}^{2+}$ but has tissue specificity. The $\mathrm{S} 100$ protein family members have aminoacid sequence with relatively high homology at $\mathrm{Ca}^{2+}$ binding locus, while the sequence at the middle hinge connective region and $\mathrm{C}$-end has relatively low homology. $\mathrm{S} 100 \mathrm{P}$ is widely distributed in human heart, brain, lung, liver, and other normal tissues, as well as in marrow and peripheral blood leukocytes, cell membrane, cytoplasm, and nucleus, with its expression in cytoplasm mainly concentrated around the nucleus [16]. In different tissues, placental tissue has the highest S100P expression, followed by oesophagus; S100P has medium expression in stomach, duodenum, colorectal, prostate and white blood cells, while has low expression in thymus, ovary, spleen, jejunum and ileum. S100 protein family is multi-function signal protein, and plays important roles in the proliferation and differentiation of cells, adhesion movement, interaction, the activation enzyme, protein phosphorylation, cell cycle regulation, gene expression transcription, apoptosis, cell internal and external $\mathrm{Ca}^{2+}$ balancemaintenance, and many other biological processes [17].

In recent years, there have been more and more researches on the S100P in digestive tract tumors, and the expression of $\mathrm{S} 100 \mathrm{P}$ in multiple tumor tissues is up. Researches show that S100P has close relationship with the occurrence and development of colorectal cancer, pancreatic cancer, and many other tumors [18]. The researches of Lines, etc. [19] show that S100P protein can be taken as the marker of pancreatic cancer, and its expression increases with the progress of precursor lesion and PanINs. In cholangiocarcinoma, S100P protein can be taken as the effective diagnosis marker of bile duct biopsy tissue, and used for distinguishing the adenocarcinoma and benign bile duct epithelial cells in bile duct biopsy [20]. Wang, etc. [21] first discovered that the expression of $\mathrm{S} 100 \mathrm{P}$ in cancer tissue and the level of S100P in serum can be taken as the prognosis marker of colorectal cancer patients. The expression level of $\mathrm{S} 100 \mathrm{P}$ in cancer tissues is significantly higher than its para-carcinoma tissues, correlates to the location of primary colorectal cancer, and presents progressive increase trend from the right colon to the left colon, and is the highest in the rectum. From Kaplan-Meier's result, the overall survival time of patients with S100P protein expression level at Phase I to Phase III is significantly shorter than patients without S100P expression in the tumor tissue, and their survival time is in negative correlation with the S100P level in the serum. $\mathrm{Li}$ Xiaoyan, etc. [22] reported that S100P protein positive rate $(56.3 \%)$ in colorectal cancer tissue is significantly higher than pericancerous mucosa and normal tissues $(3.8 \%$ and $2.5 \%$, $\mathrm{P}<0.05$ ), and the difference in lymph metastasis and TNM staging has statistic significance $(\mathrm{P}<0.05)$, but the positive rate of pericancerous mucosa and normal tissue and the difference of S100P protein positive rate of moderate-poor differentiation and well-moderate differentiation has no statistic significance $(\mathrm{P}>0.05)$. It prompts that $\mathrm{S} 100 \mathrm{P}$ protein of colorectal cancer tissue presents high expression, and has relatively big correlation with lymph node metastasis and tumor TNM staging, and has important value in the occurrence and development of colorectal cancer.

As for the inconsistent research result of S100P in gastric cancer tissues, some researchers believe that the expression is down, while other researchers believe that the expression is up. Liu, etc. [23] reported that the positive rate of S100P protein in gastric cancer and control tissue has no significant difference. By testing the pattern of gene expression of gastric cancer tissue through cDNA micro-matrix technology, Joghetaei, etc. [24] didn't discover the expression of S100P gene. Zhao Xiaomu, etc. [25] reported that the positive expression rate of $\mathrm{S} 100 \mathrm{P}$ in gastric cancer tissue is $52.9 \%(64 / 121)$, and dynamic observation discovers that the 5-year survival rate of patients with S100P positive expression is significantly higher than the patients with negative expression $[20.3 \%(13 / 64)$ V. S. 3.5\% (2/57)], but the expression level of S100P has no relationship with the differentiation degree of tumor cells, clinical staging, lymph node metastasis and remote metastasis of tumor. However, the researches of Ge, etc. [26] believe that S100P correlates to TNM staging and prognosis, the 5-year survival rate of patients with $\mathrm{S} 100 \mathrm{P}$ positive expression is significantly lower than the patients with negative expression. The researches of Diederichs, etc. [27] discovered that normal gastric mucosa nearly all expresses S100P protein, while the expression rate of gastric cancer tissue is just $52.7 \%$ (49/93), and its low expression rate has relationship with the invasion 
depth and tumor size of gastric cancer. JiaShuqin, etc. [28] reported that S100P has positive expression in normal gastric mucosa glandular tissue, $\mathrm{S} 100 \mathrm{P}$ expression is down in gastric cancer tissue, and the patients with positive expression of S100P has relatively small tumor size and relatively low staging, but S100P can't be taken as an independent affecting factor of prognosis. Researches of Jia, etc. [29] believe that low level expression of S100P in gastric cancer prompts poor prognosis, and correlates to the gastric cancer size and invasion depth, which prompts that S100P may play the role of antitumor. Zou Jianfeng and Shen Qixiao [30] believe that S100P expression drops significantly in gastric cancer, and $\mathrm{S} 100 \mathrm{P}$ has close correlation with the TNM staging, differentiation degree and lymph node metastasis and may jointly participate in the metastasis, infiltration and invasion of the gastric cancer. Qiao Xiaojuan, etc. [31] reported that the expression level of RNA which is the messenger of S100P protein in gastric cancer tissue and the positive expression rate of S100P protein is significantly lower than that of the para-carcinoma tissue, and its expression drop has relationship with the vascular cancer thrombus. This research also discovers that gastric cancer patient's pre-surgery serum S100P level is a little lower than normal people, and the serum S100P level of patients without lymph node metastasis is a little higher than that of the patients with lymph node metastasis, the patients' serum S100P level two weeks after the surgery is significantly lower than before the surgery, which prompts that S100P level drops in gastric cancer tissue and serum, and it is able to forecast reoccurrence and judge prognosis by monitoring serum S100P level change dynamically [31]. Li Bing, etc. [32] reported that the positive expression rate of $\mathrm{S} 100 \mathrm{P}$ in the gastric cancer tissue is significantly lower than normal tissue and chronic gastritis tissue. The Borrmann typing of gastric cancer is a gastric cancer typing method for progressing stage gastric cancer universally adopted domestic and overseas [33]. Some researches prove that different typing of Borrmann can affect the invasion depth of the focus, lymph node metastasis and remote metastasis, and affect the prognosis in return [34]. Compared with Type III, IV and V, Type II of Borrmann shows relatively good biological behavior and has relatively low invasion depth and lymph node metastasis. Borrmann typing can be taken as a valuable factor to simply forecast the advanced GC patients' survival rate, especially for patients who have had radical resection at Phase III (Type IV) of TNM [35].

This research result shows that the positive expression of $\mathrm{S} 100 \mathrm{P}$ protein in gastric cancer tissue is mainly located in cytoplasm, with a minority in the nucleus or on the cell membrane, and its positive rate $(51.0 \%, 51 / 100)$ is significantly lower than the control group $(P<0.001)$. With the progress of superficial gastritis, chronic atrophic gastritis with atypical hyperplasia and gastric cancer, the positive rate of $\mathrm{S} 100 \mathrm{P}$ protein drops gradually, the positive rate o $\mathrm{S} 100 \mathrm{P}$ protein is significantly lower than chronic atrophic gastritis with atypical hyperplasia, superficial gastritis and normal gastric mucosa tissue, the difference of the four groups has statistic significance $(P<0.01$ or $P<0.05)$, the difference of $\mathrm{S} 100 \mathrm{P}$ protein positive expression rate between gastric cancer and chronic atrophic gastritis with atypical hyperplasia has no statistic significance. The positive expression of S100P protein in the gastric cancer has no relationship with the patients' gender, age, tumor size, tumor position, and other clinical data $(P>0.05)$, while the difference of the differentiation degree, invasion depth, TNM staging, Borrmann typing and lymph node metastasis has statistic significance $(P<0.05)$, which is presented as differentiation degree varying from high to low, the invasion depth, TNM staging and Borrmann increase, and the lymph node metastasis and other conditions deterioration and the grade malignancy increase and positive rate drop. The low level expression of S100P protein is common in patients with poor tumor differentiation degree, deep invasion, high TNM staging and Borrmann typing, with lymph node metastasis, which indicates that the positive rate drop of S100P protein is an important indicator of poor prognosis of gastric cancer. Vice versa, too high expression level of S100P protein is common in patients with early clinical staging, good differentiation, shallow invasion, without lymph metastasis, and the rise of positive rate can be taken as the indicator for judging good prognosis of gastric cancer. The research results of most of the above scholars prompt that S100P protein plays an important role in the development and metastasis of gastric cancer. S100P protein is a negative regulator for cycle of cell which has carcinostasis, and its expression drops gradually in the occurrence and development of the gastric cancer, and it makes the invasion capability of cancer cells increase, the malignancy rise, and the reoccurrence and metastasis more possible, and the prognosis poorer.

There are some disputes on the expression of S100P protein in gastric cancer and normal gastric mucosa tissue, and the positive rate of $\mathrm{S} 100 \mathrm{P}$ in gastric cancer tissue is relatively big, varying from $18.52 \%$ to $88.0 \%[32,31]$, and the value of $\mathrm{S} 100 \mathrm{P} \mathrm{mRNA}$ and protein expression level in prognosis is also different, and may even have contrary result, which may have relationship with the following factors: different tissue types secrete S100P protein outside of the cells and are different in giving play to the capability of RAGE activating signal molecules; or after transcription, S100P protein expression regulation or the translated $\mathrm{S} 100 \mathrm{P}$ protein expression tissue specificity are different; or experiment method, antibody types, reagent stability, and positive result evaluation standard, the tester's error, the number of the cases included, clinical staging, differentiation degree, type distribution, and other factors. Therefore, a lot of farsighted researches of big samples are needed.

The researches on S100P and other indicators in gastric cancer have also achieved some progresses. Zou Jianfeng, etc. [30] had Pearson grade correlation analysis for positive expression of CD147 and S100P protein in gastric cancer tissue of different TNM stage, and discovered that the two are in significant negative correlation $(\mathrm{r}=-0.713, P<0.05)$, which has close relationship with the patients' TNM staging, differentiation degree and lymph node metastasis. This 
prompts that the over-expression of CD147 may restrain the expression of S100P protein and jointly participate in the invasion and metastasis of gastric cancer. Li Bing, etc. [32] analyzed the expression condition of S100P, CD147, and OCT4 at different stage of gastric cancer tissue and discovered that the positive rate of S100P protein in the gastric cancer is significantly lower than the control group, while CD147 and OCT4 is significantly higher than the control group, S100P protein is in negative correlation with CD147 and OCT4; low level expression of S100P protein and the high level expression of CD147 and OCT4 in gastric cancer tissue has close relationship with TNM staging and remote metastasis, the patients with remote metastasis have the positive rate of S100P protein dropped and of CD147 and OCT4 risen significantly, but has no relationship with the differentiation degree. Liu Jingyun, etc. [36] discovered that the expression of CD147 and S100P protein in gastric cancer tissue are in significant negative correlation $(\mathrm{r}=-0.708, P<0.05)$, the positive rate of CD147 in gastric cancer tissue rises while the positive rate of $\mathrm{S} 100 \mathrm{P}$ protein drops, all have close relationship with the differentiation degree, serosa invasion, TNM staging, and lymph node metastasis of the tumor.

Currently, the researches for ILK, S100P protein and other indicators in gastric cancer have been carried out, but such reports of the joint detection of the two in gastric cancer is still rare. The researches of Hou, etc.[37] discovered that the expression of ILK and S100P protein in gastric cancer is in negative correlation $(\mathrm{r}=-0.286, P<0.05)$, the positive rate of ILK in gastric cancer tissue is significantly higher than the control group, while S100P is significantly lower than the control group $(P<0.05)$. S100P positive rate of gastric cancer patients and patients of CGA with atypical hyperplasia is significantly lower than other groups $(P<0.05)$ and the expression of ILK and S100P protein in gastric cancer has relationship with the clinical staging, differentiation degree, invasion depth and lymph node and remote metastasis. The positive rate of S100P protein of patients with ILK positive expression is significantly lower than that of patient with ILK negative expression $(P<0.05)$. In gastric cancer tissue of moderate and good differentiation, with invasion not reaching the serosa, without lymph metastasis, and of Phase I and Phase II, patients with S100P protein positive and ILK negative are significantly more than patients with $\mathrm{S} 100 \mathrm{P}$ protein negative and ILK positive $(\mathrm{P}<0.01)$; however, in the gastric cancer tissue of poor differentiation or undifferentiation, with invasion reaching the serosa, with lymph node metastasis, and of Phase III and Phase IV, patients with S100P protein negative and ILK positive are significantly higher than patients with S100P protein positive and ILK negative $(P<0.05$ or $P<0.01)$. Joint detection of the expression of ILK and $\mathrm{S} 100 \mathrm{P}$ in the gastric cancer tissue is favorable for its diagnosis, clinical observation and prognosis judgment.

Researches discover that ILK participates in the regulation of cells through phosphorylation [38] and many other signal transduction channels, and plays an important role in cell proliferation, adhesion, apoptosis, migration, etc.[39], has abnormal expression in various malignant tumors, and affects the cell proliferation, differentiation, migration, invasion and blood vessel generation [40]. S100P is a signal protein with multiple functions, plays an important role in activation of enzyme, protein phosphorylation, cell proliferation and differentiation, apoptosis, gene expression and transcription, cell adhesion and interaction between cells, and maintaining the $\mathrm{Ca}^{2+}$ balance inside and outside the cells, etc. Its abnormal expression in various tumors affects the cell proliferation, growth, invasion and metastasis through various signal channels [41] and promotes the generation of blood vessels, tumor proliferation, invasion and metastasis [42-44]. However, the action mechanism of ILK and S100P protein in the occurrence and development process of gastric cancer is still not clear. Based on the multiple functions and the role in signal transduction channels of the two, this paper discuss the signal transduction channels of the two in depth, researches their action mechanism in the occurrence and development of gastric cancer, which will provide theoretical basis for early diagnosis, rational treatment, prognosis and effective prevention and control and open new channels for discussing the pathogenesis of gastric cancer. However, the mechanism of action of ILK and S100P proteins in the occurrence and development of gastric cancer is not very clear. Further prospective studies with large samples should be carried out, Based on their versatility and their role in the signal transduction pathway, the signal transduction pathway of ILK and S100P proteins should be further explored to study their mechanism in the occurrence and development of gastric cancer. It will provide theoretical basis for the early diagnosis, reasonable treatment, prognosis judgment and effective prevention and treatment of gastric cancer, and open up a new way for the discussion of the pathogenesis of gastric cancer.

In summary, the expression of S100P in gastric cancer has relationship with the differentiation degree, TNM staging, Borrmann typing and lymph node metastasis, and prompts that $\mathrm{S} 100 \mathrm{P}$ is a tumor marker with potential value. As per evidence-based laboratory medicine, screening several tumor markers with high sensitivity and specificity for joint detection expects to provide meaningful help for early diagnosis, TNM staging and prognosis evaluation. It will play an important role for gene-targeted therapy and be of important significance for improving the gastric cancer patients' life quality and survival rate to look for effective regulating gene which affects tumor cell proliferation, apoptosis, invasion and metastasis and molecular target which affects prognosis and to discuss the pathogenesis from the perspective of molecular biology.

\section{Conclusion}

The positive rate of $\mathrm{S} 100 \mathrm{P}$ in gastric cancer tissue is significantly lower than the para-carcinoma tissue; the patients with poorerdifferentiation degree, deeper invasion, later TNM staging and Borrmann typing and lymph node metastasis have lower positive rate of S100P, which proves that the low expression of S100P participates in the occurrence, development, invasion and metastasis of gastric cancer. The 
positive expression of S100P has significant correlation with the prognosis of gastric cancer; the lower the positive rate is, the poorer the prognosis is. $\mathrm{S} 100 \mathrm{P}$ is an independent hazardous factor affecting patients' prognosis and has some value for judging the patients' prognosis. The positive rate of $\mathrm{S} 100 \mathrm{P}$ in gastric cancer tissue has no relationship with the patients' gender, age, tumor size and position, and Lauren typing. The positive rate of ILK and S100P protein in the gastric cancer tissue is in negative correlation, patients with ILK negative but S100P positive have relatively good prognosis, while patients with ILK positive and S100P negative have relatively poor prognosis, which prompts that the two may have antagonism in the occurrence, development, invasion and metastasis of gastric cancer. It may provide some reference basis for the gene therapy and drug treatment of gastric cancer to constrain ILK activity or improve S100P activity.

\section{References}

[1] Bray F, Ferlay J, Soerjomataram I, et al. Global cancer statistics 2018: GLOBOCAN estimates of incidence andmortalityworldwide for 36 cancers in 185 countries [J]. CA Cancer J Clin, 2018, 68 (6): 394-424.

[2] Zhou JS, Zheng RS, Zhuang GH, et al. Analysis on the trend of gastric cancer incidence and age change in cancer registration regions of China [J]. J Applied Oncology 2000 to 2015 [J]. 2020, 34 (1): $1-5$.

[3] Song ZH, Xu XN, Li KL, et al., Research progress on etiology of gastric cancer [J]. Chin Med J Metall Indus, 2020, 37 (5): 509-511.

[4] Li SS, Xu H, Han XC. Research progress of S100P-a new member ofthe S100 family and its relationship with tumor [J]. Chin Med Herald, 2015, 12 (12): 45-49.

[5] Wang G, Platt-Higgins A, Carroll J, et al. Induction of metastasis by $\mathrm{S} 100 \mathrm{P}$ in a rat mammary model and its association with poor survival of breast cancer patients $[\mathrm{J}]$. Cancer Res, 2006, 66 (2): 1199-1207.

[6] Surowiak P, Maciejczyk A, Materna V, et al. Unfavourable prognostic significance of $\mathrm{S} 100 \mathrm{P}$ expression in ovarian cancers [J]. Histopathology. 2007, 51 (1): 125-128.

[7] Hou JZ, Li Y. Research Development of Calcium-Binding Protein S100P in Digestive Tumor [J]. Med Recap, 2017, 23 (19): 3796-3800.

[8] Ministry of Health of the People's Republic of China. Standard practice for diagnosis and treatment of Gastric Cancer (2011 edition) $[\mathrm{J}]$. Chinese Journal of Medical Frontier (electronic version) 2012, 4 (5): 62-71.

[9] Song J, Dong SL, Duan JP, et al. Expression of SDF-1/CXCR4 in gastriccarcinoma of different Borrmanntype and its cli-nical significances [J]. Chin J Clinicians (Electronic Edition), 2015, 9 (20): 3691-3695.

[10] M. B. Aminetal. American Joint Committee on Cáncer A JCC Cáncer Staging M anual, Eighth Edition [J]. 2017, 203-220.
[11] Feng RM, Zong YN, Cao SM, et al. Current cancer situation in China: Good or bad news from the 2018 Global Cancer Statistics? [J]. Cancer Commun (Lond). 2019. 39 (1): 22.

[12] Wang SM, Zheng RS, Zhang SW, et al. Epidemiological characteristics of gastric cancer in China, 2015 [J]. Chin J Epidemiol. 2019, 40 (12): 1517-1521.

[13] Wang YK, Li ZY, Shan F, et al. Current status of diagnosis and treatment of early gastric cancer in China-Data from China Gastrointestinal Cancer Surgery Union Chin J Gastrointest Sur, 2018, 21 (2): 169-174.

[14] Niu Y, Shao Z, Wang H, et al. LASP1-S100A11 axis promotes colorectal cancer aggressiveness by modulating TGF $\beta / \mathrm{Smad}$ signaling [J]. Scientific Reports, 2016, 6 (1): 26112.

[15] Li D, Zeng Z, Wu J, et al. Research Progress of Effects and Mechanism of S100 Protein in the Occurrence and Development of Colorectal Cancer [J]. Med Reca, 2017, 23 (8): 1533-1538.

[16] Du M, Wang G, Ismail TM, et al. S100P dissociates myosin IIA fi laments and focal adhesion sites to reducecell adhesionand enhance cell migration [J]. J BiolChem 2012, 287 (19): 15330-15344.

[17] Poeter M, Radke S, Koese M. Disruption of the annexin A1/S100A11 compl-ex increases the migration and clonogenic growth by dysregulatingepithe-lial growth factor (EGF) signaling [J]. BiochimBiophysActa [J]. 2013, 1833 (7): 1700-1711.

[18] Huang M Y, Wang H M, Chang H J, et al. Overexpression of S100B, TM4SF4, and OLFM4 Genes Is Correlated with Liver Metastasis in Taiwanese Colorectal Cancer Patients [J]. DNA and cell biology, 2012, 31 (1): 43-49.

[19] Lines KE, Chelala C, Dmitrovic B, et al. S100P-binding protein, S100P-BP, mediates adhesion through regulation of cathepsin $\mathrm{Z}$ in pancreatic cancer cells [J]. Am J Pathol, 2012, 180 (4): 1485-1494.

[20] Prica F, Radon T, Cheng Y, et al. The life and works of S100P-from conception to cancer [J]. Am J Cancer Res, 2016, 6 (2): $562-576$.

[21] Wang Q, Zhang YN, Lin GL, et al. S100P, a potential novel prognosticmarker in colorectal cancer [J]. Oncol Rep, 2012, 28 (1): 303-310.

[22] Li XY, Zhang QF, Zhang HL, et al. Expression and significance of S100P protein in colorectal carcinoma [J]. Mode Med \& Health Rese, 2019, 3 (3): 82-84.

[23] Liu J, Li X, Dong GL, et al. Insilico analysis and verification of S100 gene expression in gastric Cancen [J]. BMC Cancer, 2008, 8: 261 .

[24] Joghetaei N, Akhyari P, Ranch BH, et al. Extracellular matrix metalloproteinase inducer (CD 147) and membrance type 1-matrix metalloproteinaseare expressed on tissue macrophages in caleific aortic stenosis and induce transmigration in an artificial valvemodel $[\mathrm{J}]$. J ThoracGardiovascSurg, 2011, 142 (1): 191-198.

[25] Zhao XM, Bai ZG, Ma XM, et al. Impact of S100P expression on clinical outcomes of gastric cancer pat ients with adjuvant chemotherapy of oxaliplatin and its mechanisms $[\mathrm{J}]$. Chin $\mathrm{J}$ Surg, 2010, 48 (13): 1004-1008. 
[26] Ge F, Wang C, Wang W, et al. S100P predicts prognosis and drugresistance in gastric cancer [J]. Int J Biol Markers, 2013, 28 (4): 387-392.

[27] Diederichs S, Bulk E, Steffen B, et al. S100 family members and trypsinogens are predictors of distant metastasis and survival in early-stage non-small cell lung cancer [J]. Cancer Res, 2004, 64 (16): 5564-5569.

[28] Jia SQ, Ji JF, Su XL. Down-regulated Expression of S100P in Gastric Cancer and Its Significance [J]. Cancer prev\& treat research 2011, 38 (4): 423-426.

[29] Jia SQ, Niu ZJ, Zhang LH, et al. Identification of prognosis-relatedproteins in advanced gastric cancer by mass spectrometry-based comparative proteomics [J]. J Cancer Res ClinOncol, 2009, 135 (3): 403-411.

[30] Zhou JF, Shen QX. Expression of CD147 and S100p in gastric cancer tissue and its clinical significance Significance of research [J]. Mode J IntegTradi Chin and West Med, 2016, 25 (9): 973-975.

[31] Qiao XJ, Su XL, Shi YH, et al. Expressions of S100 calcium-binding protein $\mathrm{P}$ in gastric cancer tissue and serum of patients with gastrc cancer and their clinical significances [J]. $\mathrm{J}$ Jilin Universty (Med Edition), 2015, 41 (4): 830-835.

[32] Li B, Luo LL, Lai DN. Expression and significance of S100P, CD147 and OCT4 in different stages of TNM of gastric cancer [J]. J Hebei Med, 2016, 38 (4): 492-495.

[33] Zhan HJ, Liang H, Liu HM, et al. Prognostic analysis of intraoperative chemohyperthermic peritoneal perfusion in patients with advanced gastric cancer of different pathological types and Borrmann's classifications [J]. Chin J ClinOncol, 2020, 47 (3): 135-139.

[34] Wang ZH, Cao L, Liang P, et al. Analysis of risk factors for lymph node groups 5 and 6 metastasis in gastric cancer [J]. J Surg Concepts Prac, 2020, 25 (3): 217-221.

[35] Song XH, Zhang WH, Kai-Liu, et al. Prognostic impact of
Borrmann classification on advanced gastric cancer: a retros-pective cohort from a single institution in western China [J]. World J SurgOncol. 2020, 18 (1): 204.

[36] Liu JY, Jin SL, Liu BZ. Expression of CD147 and S100P in gastric cancer tissues and its clinical significance [J]. J North Sichuan Med Colle, 2017, 32 (4): 583-586.

[37] Hou JZ, Li Y. Expression of Integrin-linked Kinase in Gastric Cancer and Its Relationship with Clinicopathological Characteristics [J]. American Journal of Biomedical and Life Sciences. 2020, 8 (4): 119-125.

[38] Bhushan B, Edwards G, Desai A, et al. Liver-Specific Deletion of Integr-in-Linked Kinase in Mice Attenuates Hepatotoxicity and Improves Liver Regeneration After Acetaminophen Overdose [J]. Gene Expr. 2016, 17 (1): 35-45.

[39] 38Shen H, Ma JL, Zhang Y, et al. Integrin-linked kinase overexpression promotes epith-elial-mesenchymal transition via nuclear factor- $\mathrm{KB}$ signaling in colorectal cancer cells. World J Gastroenterol. 2016, 22 (15): 3969-3977.

[40] 39Chou CC, Chuang HC, Salunke SB, et al. A novel HIF-1 $\alpha$-integrin-Linked kinase regulatory loop that facilitates hypoxia-induced HIF-1 $\alpha$ expression and epithelial-mesenchymal transition in cancer cells. [J]. Oncotarget, 2015, 6 (10): 8271-8285.

[41] Lin FY, Jiang L. Current Research Advances in Relationship betweenS100P and Digestive Cancer [J]. Chin J Cell Biol 2013, 35 (5): 734-740.

[42] Bresnick AR, Weber DJ, Zimmer DB. S100 proteins in cancer [J]. Nat Rev Cancer, 2015, 15 (2): 96-109.

[43] Hamada S, Satoh K, Hirota M, et al. Calcium-binding protein $\mathrm{S} 100 \mathrm{P}$ is a novel diagnostic marker of cholangiocarcinoma $[\mathrm{J}]$. Cancer Sci, 2011, 102 (1): 150-156.

[44] Zhang Q, Hu HL, Shi X et al. Construction of Shrnalentiviral vector of S100P gene and its effect on biological behavior of MGC-803 cells [J]. J Southeast Univ (Med Sci Edi), 2015, 34 (1): 65-70. 